\title{
Review of Towards Sustainable Use of Rangelands in North-West China
}

Tracy V Hruska

\author{
Book details \\ Squires, V, Hua, L, Zhang, D and Li, G (eds.) \\ Towards Sustainable Use of Rangelands in North-West China. \\ New York: Springer, 2010. \\ xxxi, 353 pages, ISBN 978-90-481-9621-0 e-ISBN 978-90-481-9622-7, DOI 10.1007/978-90-481-9622-7
}

Keywords: China; Pastoralism; Rangeland; Development; Grassland; Degradation; Livestock

Analyses of Chinese rangeland management are frequently divided on the identification of problems and solutions based on the nationality of the author. While most authors agree that grassland quality is declining and that pastoralist livelihoods are threatened with insolvency, Western authors tend to focus on the loss of grazing area and mobility due to landscape fragmentation caused by privatization policies, cropland intrusion, and insecure land tenure. Chinese authors, in contrast, tend to focus on the environmental damages caused by overstocking and overgrazing, and the corresponding need to raise herder incomes while decreasing livestock numbers, typically through agro-pastoral integration. This contrast in perspectives is on display in Towards Sustainable Use and unfortunately goes unanalysed.

The book's 15 chapters are written by a mix of Western - mostly Australian, but also Canadian - and Chinese authors, with a near-even split of lead authorships. Tone and style are fairly consistent, but the principles and solutions espoused frequently differ or are outright contradictory. Such internal disparity is inconvenient for those hoping to take action based on consensus, but is a realistic reflection of professional opinion in the field. Regardless of the specific tack, taking action is what this book is promoting. While the preface and chapter titles give the impression of a book on ecological restoration, the real focus is on

\footnotetext{
Correspondence: t.hruska@berkeley.edu
}

Department of Environmental Science, Policy, and Management, University of California - Berkeley, 130 Mulford Hall MC 3110, Berkeley, CA 94720-3110, USA

\section{Springer}

(C) 2014 Hruska; licensee Springer. This is an Open Access article distributed under the terms of the Creative Commons Attribution License (http://creativecommons.org/licenses/by/4.0), which permits unrestricted use, distribution, and reproduction in any medium, provided the original work is properly credited. sustainable development, with Western development agencies and, to a lesser degree, researchers as the intended audience. The focus on development is reflected in acknowledgements of support from development and research agencies and the World Bank/Global Environment Facility 'Gansu Xinjiang Pastoral Development' project, which is cited frequently throughout the book.

The breadth of Towards Sustainable Use is wide and seems intended to present potential development agencies in the region with a comprehensive picture of both problems and solutions. The five sections comprise a regional introduction, explanations of rangeland ecology and restoration potential, broader environmental concerns in the local context (including carbon sequestration), economics and improved agro-pastoral integration (including land tenure), and steps to move forward. While several important issues go inexplicably unmentioned (to be discussed later), the breadth of subject matter reflects the authors' view that pastoral systems involve inextricably linked human, livestock, and land components that must be considered holistically.

The broad strokes of the problems on China's rangelands are quite clear, despite variance in the details. The basic story is that the rangelands, principally of Xinjiang, Gansu, Inner Mongolia, and Qinghai provinces, are becoming severely degraded due to overgrazing by livestock. Livestock numbers are substantially higher now than those prior to 1949 , with the most significant increases occurring since the reforms of the early 1980s. Despite high livestock numbers and increasing domestic demand for livestock products, most pastoralists, all of whom are ethnic 
minorities, are still quite poor, though often better off than rural farmers in the same regions. The challenge is thus to increase herder income while decreasing grazing pressure and/or decreasing livestock numbers.

As presented by Squires et al., one main avenue for intervention lies in the fact that livestock health and quality are at present fairly low due to inadequate feed, especially over the region's long, harsh winters. Increasing forage supply from rangelands is difficult, which is why most authors recommend improving agro-pastoral integration. One likely improvement recommended frequently throughout the book, which is cited to have had favourable results in field trials, is the introduction of supplemental fodder and winter warming pens in combination with reduced overall livestock numbers. When practised correctly, supplemental winter feedings - typically of fodder crops, purchased hay, or agricultural by-products and warming pens result in higher body weight, and growth and reproduction rates. Especially when paired with improved marketing strategies, breed varieties, and herd management, this improved animal health translates to higher sale price and increased income for herders despite smaller total herd sizes. Smaller herd sizes mean reduced grazing pressure and an opportunity for rangeland recovery.

These solutions may not work out so well in practice, however. As several chapters admit, the potential for pen feeding is limited by poor infrastructure, low feed availability and high feed cost, lack of feed storage capacity, and low access to credit, among other factors. The chapters that list Victor Squires as first author tend to be particularly doubtful of a rosy future for further agro-pastoral integration (Chapters 1, 2, 3, 5, and 15). There are several reasons for this skepticism, all of which are stated in quiet, non-confrontational terms, and most of which go entirely unmentioned in chapters with a Chinese or Western development agency first author. The following sections are devoted to these points of controversy and to important issues that are omitted from discussion in the book.

\section{Disagreements and contradictions}

For those readers familiar with rangeland ecology and/or Chinese pastoral areas, several issues will likely stand out in this book as being controversial or inconsistent. The first of these relates to fundamental interpretations of rangeland ecology. Chapters listing Victor Squires as first author clearly state (e.g. p. 54) that rangelands in northwest China are non-equilibrium systems whose productivity is largely determined by stochastic events and variable rainfall, and which are best described by state-and-transition models. Such a view suggests that vegetation growth and thus livestock carrying capacity are temporally and spatially heterogeneous, and is now a typical Western understanding of arid and semi-arid rangelands. As stated in Chapter 5 (pp. 96 to 97), 'There is no single optimum [stocking] density and, hence, little point to simply characterizing an area as overstocked'. In contrast, Chinese state policy (Ho 2001) and some sections of Towards Sustainable Use (especially Chapter 6) are based on equilibrium, climax models of rangeland ecology. According to this view, range health and/or degradation can be measured by progress toward the climax state, and carrying capacity can be measured as a fixed quantity irrespective of rainfall (except possibly drought).

The consequences of these opposed ecological interpretations for management are profound. If the nonequilibrium view holds, not only are the mandatory stock reductions and grazing bans enacted by the state of questionable worth, but the very concept of privatizing land into parcels that restrict herd movement becomes questionable. Indeed, Squires et al. place much of the blame for rangeland degradation on the Household Contract Responsibility System, a policy enacted in 1983 that broke up the former state communes into individual allotments. This parcelling of the landscape has allowed for extensive conversion of rangeland to cropland (started in the 1950s, largely by Han Chinese immigrants from the east), fracturing of traditional seasonal migration routes, and exploitation by wealthy elites. It has also eliminated much of the flexibility and mobility that traditionally made pastoralism on arid rangeland possible and even sustainable.

Flexibility and mobility were key components of nomadic pastoral systems and are supported in the literature on the premise that grazing pressure must vary to match spatially and temporally varied rainfall and forage production (Behnke et al. 1993; Scoones 1994). Squires concurs with this sentiment and points out that nomadic pastoral systems were a proven technology, while modern agropastoral systems are as yet uncertain (p. 16). Towards Sustainable Use neither directly challenges nor offers alternatives to Chinese state policies that restrict mobility while providing production goals and inflexible stocking rates, however. Suggestions to initiate rest rotation grazing systems (e.g. p. 68) ignore the fact that little quantitative support for this practice exists in the literature (Briske et al. 2011). The book also does not mention the large study headed by Humphrey and Sneath (1996; also see Sneath 1998) which showed that rangelands in Inner Asia with higher mobility suffered less degradation than lower mobility areas despite comparable stocking rates.

\section{Omissions}

Towards Sustainable Use makes three especially glaring omissions that are worth mentioning here. The first is the lack of quantified definition of 'degradation', despite the term's ubiquitous application to rangelands. One 
study (Harris 2010) cited frequently in the book claims that the true extent of degradation is uncertain given the poor quality and low frequency of actual monitoring, but this argument is never seriously applied.

The second omission is the careful sidestepping of the fact that sedentarization of herders is a major policy goal of China and is enforced by law and massive investments in infrastructure (Fan et al. 2013; Millward 2007). Agropastoral integration is thus politically motivated, beyond whatever ecological or economic benefits it is thought to achieve, and herders' political marginalization may at least partially explain their slow adoption of such practices.

The third omission is irrigation. Northwest China is largely semi-arid or arid, and recent agricultural gains have been achieved with extensive irrigation, especially for cotton, a major cash crop (Millward 2007). Increased use of irrigation has resulted in depleted water tables and disappearing lakes and rivers, and is likely contributing to the increasingly common sand storms (Squires and Kebin 2009). Increasing agro-pastoral integration, including irrigated pastures, implies strengthening the regional reliance on groundwater and surface water withdrawals, which is likely unsustainable already.

\section{In conclusion}

For readers whose work will take them to China for the first time, Towards Sustainable Use provides a useful overview of the economic and resource-related challenges facing pastoralist communities, along with some possible developmental interventions. The significant conflicts in ecological interpretation in play, plus inadequate discussion of herd mobility, the limits of agriculture, and a complete lack of perspective from the herders themselves make the book incomplete, however, and readers had best consult additional sources if they hope to understand the complexities of Chinese rangelands.

\section{Competing interests}

The author declares that he has no competing interests.

Received: 23 June 2014 Accepted: 24 June 2014

Published online: 30 July 2014

\section{References}

Behnke, Roy H, lan Scoones, and Carol Kerven. 1993. Range ecology at disequilibrium: New models of natural variability and pastoral adaptation in African savannas. London: Overseas Development Institute

Briske, David D, Justin D Derner, Daniel G Milchunas, and Ken W Tate. 2011. An evidence-based assessment of prescribed grazing practices. In Conservation benefits of rangeland practices: Assessment, recommendations, and knowledge gaps, ed. David D Briske, 21-74. Washington, DC: USDA-NRCS.

Fan, Mingming, Wenjun Li, Chengcheng Zhang, and Lanhai Li. 2013. Impacts of nomad sedentarization on social and ecological systems at multiple scales in Xinjiang Uyghur Autonomous Region, China. Ambio doi:10.1007/s13280013-0445-z

Harris, RB. 2010. Rangeland degradation on the Qinghai-Tibetan plateau: A review of the evidence of its magnitude and causes. Journal of Arid Environments 74(1): 1-12
Ho, Peter. 2001. Rangeland degradation in north China revisited? A preliminary statistical analysis to validate non-equilibrium range ecology. Journal of Development Studies 37(3): 99-133. doi:10.1080/00220380412331321991.

Humphrey, Caroline and David Sneath. 1996. Culture and environment in Inner Asia, vol. 1. Cambridge: White Horse Press

Millward, James A. 2007. Eurasian crossroads: A history of Xinjiang. London: Hurst \& Co.

Scoones, lan. 1994. Living with uncertainty: New directions in pastoral development in Africa, vol. 6. London: Intermediate Technology Publications.

Sneath, David. 1998. State policy and pasture degradation in Inner Asia. Science 281(5380): 1147-1148

Squires, Victor R, and Zhang Kebin. 2009. The context for the study of rangeland degradation and recovery in China's pastoral lands. In Rangeland degradation and recovery in China's pastoral lands, ed. Victor R Squires, Lu Xinshi, Lu Qi, Wang Tao, and Yang Youlin, 3-14. Cambridge, MA: CABI.

doi:10.1186/s13570-014-0011-8

Cite this article as: Hruska: Review of Towards Sustainable Use of Rangelands in North-West China. Pastoralism: Research, Policy and Practice 2014 4:11.

\section{Submit your manuscript to a SpringerOpen ${ }^{\circ}$ journal and benefit from:}

- Convenient online submission

Rigorous peer review

- Immediate publication on acceptance

- Open access: articles freely available online

- High visibility within the field

- Retaining the copyright to your article

Submit your next manuscript at springeropen.com 